\title{
Observation and Analysis of Meteorological Conditions for Icing of Wires in Guizhou, China
}

\author{
Jifen Wen', Ran Jia ${ }^{2}$, Yuxiang Peng ${ }^{*}$ \\ ${ }^{1}$ Guizhou Provincial Office of Weather Modification, Guiyang, China \\ ${ }^{2}$ Key Laboratory of Atmospheric Physics and Atmospheric Environment, Nanjing University of Information \\ Science \& Technology, Nanjing, China \\ Email: *1070792379@qq.com
}

How to cite this paper: Wen, J. F., Jia, R., \& Peng, Y. X. (2019). Observation and Analysis of Meteorological Conditions for Icing of Wires in Guizhou, China. Journal of Geoscience and Environment Protection, 7,214-230.

https://doi.org/10.4236/gep.2019.79015

Received: January 4, 2019

Accepted: September 24, 2019

Published: September 27, 2019

Copyright $\odot 2019$ by author(s) and Scientific Research Publishing Inc. This work is licensed under the Creative Commons Attribution International License (CC BY 4.0).

http://creativecommons.org/licenses/by/4.0/

\section{Open Access}

\begin{abstract}
Icing of wires is a product of rain, fog, and freezing rain, and is a common meteorological disaster in winter in Guizhou Province of China. It is extremely harmful to facilities such as power transmission and communication lines, and has caused huge economic loss up to 48.9566 billion dollars a year. Based on the meteorological records of Guizhou from 1967, we analyze the meteorological characteristics during the icing of wires, and obtain the temperature, wind speed and direction conditions of the ice accident. The icing of wires is carried out by supercooling raindrops, freezing of the clouds, freezing and spreading on the wires. Different types of supercooled raindrops and cloud freezing and freezing processes will form different types of ice accretion; wind direction and wind speed will affect the growth of ice accretion by changing the speed of sub-cooling raindrops and cloud falling. The weight of rain-type ice accretion is between 24 and $152 \mathrm{~g}$, and the weight of smog-type ice is between $40-76 \mathrm{~g}$. The average ice density of these two places can be calculated to be $0.2-0.5 \mathrm{~g} / \mathrm{cm}^{3}$. The longer the icing of wires, the higher the ice disaster rate.
\end{abstract}

\section{Keywords}

Rain, Smog, Icing of Wires, Weather Conditions

\section{Introduction}

Icing of wires is a product of rain, fog, and freezing rain, and is a common meteorological disaster in winter in Guizhou. It is extremely harmful to facilities such as power transmission, communication lines and transportation, and will bring huge losses to the national economy. For example, during the rainy and 
hazy weather from mid-January to mid-February 2008, 88 counties (cities, districts) in the province were affected to varying degrees, traffic was severely blocked, power communication facilities were seriously damaged, and the province's power grid was cracked into 4 isolated operational pieces. There are 5075 disaster-stricken lines in Guizhou Power Grid. This includes $29500 \mathrm{kV}$ lines, 94 $220 \mathrm{kV}$ lines and $277110 \mathrm{kV}$ lines. This also caused the collapse of 282 electric towers in $500 \mathrm{kV}$ lines in Guizhou Power Grid, 235 electric towers collapsed in $220 \mathrm{kV}$ lines, and 598 electric poles and electric towers collapsed in $110 \mathrm{kV}$ lines. The above caused the province's power grid to be in a state of paralysis. At the time of the province, the number of base stations that interrupt communication due to power outages reached 8542 , accounting for $50 \%$ of the total. The direct economic loss caused by the disaster in the province was RMB 34.485 billion Yuan, equivalent to 48.9566 billion US dollars.

Icing of wires is in the process of rain and haze. The power and communication departments call it icing of wires. The icing of wires adds extra load to overhead lines such as electricity and communication. Accidents such as broken wires and reversing rods may occur; in addition, when the ice accretes and melts, it is easy to generate electric flashovers, which may damage the insulators; after the icing of wires in the communication lines, the power carrier communication equipment may be degraded, resulting in an increase in noise and making it difficult to talk on phone, etc. The power supply interruption caused by the icing of wires, the power outage accident, and the tower collapse accident in the EHV transmission line tower have brought huge losses to the national economy.

Since the first record of icing of wires accident in the United States in 1932, countries around the world have been studying the problem of icing of wires. Based on the relevant meteorological data, the research work to predict the icing of wires load through theoretical models has been carried out for more than 50 years (Liu et al., 2001). A few developed countries and China have established Guanbing Station (Tan, 1982), and on the basis of long-term accumulation of data, the law of the variation of ice diameter with altitude is summarized. These studies have a certain significance for the selection of the overhead path of the wire, but this only reflects the climatic characteristics of icing of wires, and does not involve the substantive study of the formation mechanism of icing of wires (Makkonen, 1981). In theory, there are some studies that numerically simulate icing growth (Makkonen, 1984) and compare and verify them through wind tunnel tests (Loxowski et al., 1983), revealing the relative importance of these factors to ice accretion. But after all, it only reflects the law of ideal conditions, not the actual icing of wires. Meteorologists from Guizhou, Qinghai, Henan, Hunan and other provinces of China studied the temporal and spatial distribution and meteorological characteristics of icing of wires. The research on the maximum weight, water content, etc., mainly derived from the icing of wires characteristics of the province, provides a certain reference for the defense of the province's ice accidents. The quantitative study is always in a stagnant phase because of the discontinuity and incompleteness of the observations. The above 
problems still exist in the meteorological observations of Guizhou based on this paper.

Guizhou is the province with the most rainy weather in China. Due to the ups and downs of the mountains in the province, the river valleys are vertical and horizontal, and the wires are seriously iced. There are two largest areas for rain and smog days, one is in the west of Weining, Dafang and Shuicheng, and the other is Kaiyang. Shuicheng is the largest industrial city in western Guizhou, with the highest icing of wires in the province. There is a heavy ice area near Jiuyong Line near Kaiyang (Luo, 1994).

According to the law of the occurrence of icing of wires in the mountainous areas of Guizhou Plateau, this paper selects the external field observations, line observations and observations of county meteorological stations in Zunyi, Shuicheng and Kaiyang from 1967 to 1994, and the weather and wires for rain and fog. The formation conditions of ice accretion were discussed, and the meteorological conditions for icing of wires were analyzed.

\section{Data and Methods}

Selected data: 1) Outfield data: Firstly, two representative heavy fog areas in Guizhou Province (see Figure 1) were selected for special outfield observations, namely, Lushan Mountain in the north and Qiyun Mountain in Guiyang in the central part, with altitudes of $1736 \mathrm{~m}$ and $1658 \mathrm{~m}$ respectively. The observation time was 1990, the winter of 1994. Observations include cloud droplets in the cloud, water content, temperature, wind direction, wind speed, visibility, long diameter and short diameter of icing of wires. The cloud droplet spectrum and water content were collected by the domestic three-use drop spectrometer horizontal suction method. The ice accretion observation has a special smog observation frame, which is set to $1 \mathrm{~m}$ long $8 \#$ wire in the east, west and north direction from the ground $1.5 \mathrm{~m}$ high, including: 00:00 to 9:08 on January 3, 1990. The temperature, wind direction and wind speed data of $152 \mathrm{~h}$ were observed

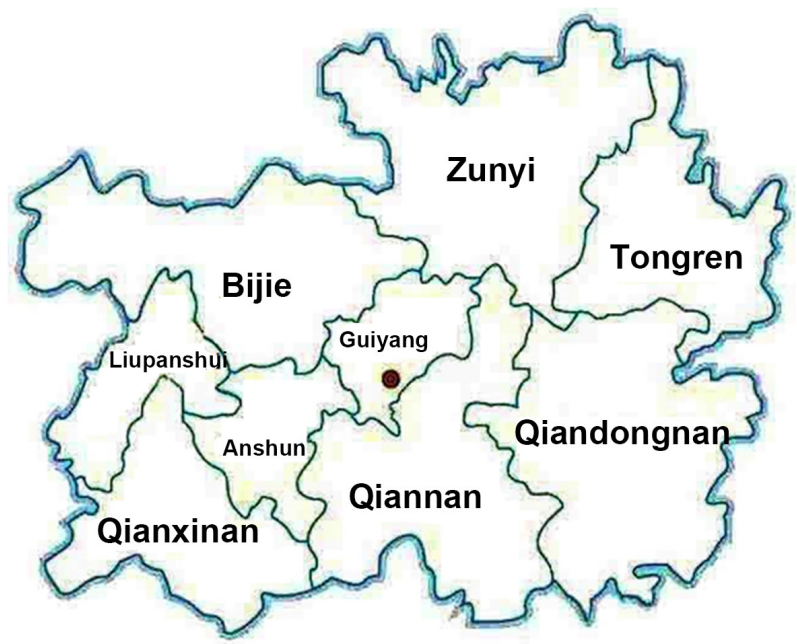

Figure 1. Guizhou Province schematic map. 
continuously in Zunyi Lushan, divided into two observation points, $1 \#$ is the stadium, the altitude is $1736 \mathrm{~m}, 2$ is under the TV tower, the altitude is $1780 \mathrm{~m}$; 199417 From 23:00 to 21:00 on the 21 st, the temperature, wind direction and wind speed data of the 81-hour continuous observation in the Yunwu Mountain of Guiyang at an altitude of $1658 \mathrm{~m}$, as well as the ice diameter and ice thickness data. 2) Line data: ice accretion parameters in the water-discharge line from 1967 to 1989 (Lipanshui to Panxian) and Jiuzong line. 3) County Meteorological Station Information: Icing of wires observations from the county meteorological stations in Shuicheng and Kaiyang from 1967 to 1989.

The observations were carried out on icing of wires shelf according to the Ground Observation Specification, and the wire diameter was $4 \mathrm{~mm}$. From the formation of icing of wires from the wires on the ice shelf, until the icing of wires disappears, it is called an ice accretion process. When observing, the maximum diameter and thickness of each ice accretion process shall be determined, in millimeters, taking an integer. When the measured diameter reaches a certain value, the maximum weight of icing of wires, in $\mathrm{g} / \mathrm{m}$, must be determined according to the type of ice accretion of different wires (rain, haze and wet snow). The formation and variation of ice accretion is complicated. Sometimes there is icing of wires on one direction of the wire, no direction in the other direction, or the start and end time of the two are different, or one direction reaches the weight measurement standard, and the other direction reaches the end. Weighing standards, etc., the observations should be recorded according to the situation. The observation of the air temperature, the wind direction, and the wind speed is performed after each measurement of the ice weight, and when the ice weight is not observed, the ice thickness is measured.

\section{Analysis of the Formation Conditions for Icing of Wires}

Rain rafts are hard ice layers that are cooled by liquid precipitation and freeze directly after hitting objects on the ground. Generally, rain formation is accompanied by liquid precipitation, such as drizzle, rain or sleet. The smog is a milky white ice crystal formed by the condensation of water vapor in the air or the supercooled mist directly on the object. It is formed when the temperature is low, the humidity is high, or there is light fog or fog. It can occur with light fog, fog, or alone when humidity is high (Zhang, 1999). Rain, smog, frozen on the wire or wet snow frozen on the wire called icing of wires. Frost, dry snowflakes, and adhering raindrops attached to the wires freeze a small amount of ice due to falling temperatures below zero, and no icing of wires (China Meteorological Administration, 2003).

Since icing of wires in the process of rain, haze and fog, and their formation conditions are similar and closely related, the weather conditions formed by rain and haze should be analyzed to find out the commonalities between them.

\subsection{Weather Conditions Caused by Rain and Haze}

Rainy weather is a special case of precipitation in the winter half year. The cha- 
racteristics of a wide range of weather conditions when rainstorms occur are: in most cases, the mid-latitude $500 \mathrm{hpa}$ in Asia is a transverse trough, the westerly wind is strong, the westerly winds are small and small, and the small trough makes the cold air sub-segment southward. At the same time, the south west wind has a deep trough in the Bay of Bengal, and there is a strong southwesterly airflow in front of the trough. The cold and warm air at high and low levels meets in our country. The ground temperature is generally between $-5^{\circ} \mathrm{C}$ and $0^{\circ} \mathrm{C}$ (the highest probability of raining at $-1^{\circ} \mathrm{C}$ to $0^{\circ} \mathrm{C}$ ). The surface wind direction is mostly N-NE. The strong southwesterly wind of $700 \mathrm{hpa}$ brings warm and humid air, and the temperature on the $700 \mathrm{hPa}$ surface in Jiangnan can reach $4^{\circ} \mathrm{C}-6^{\circ} \mathrm{C}$. The hollow warm and humid air slides on the low-level cold air cushion, which is a very favorable condition for rainy weather.

According to the analysis of a large number of rainy weather profiles in China, the Central Meteorological Observatory believes that the vertical structure of the atmosphere can be divided into high-altitude ice crystal layer, hollow warm layer and low-altitude cold layer (Zhu et al., 2000).

Rainfall in Guizhou almost occurs in the stable layered cloud of the static frontal zone, with a thickness of 1500 to $5000 \mathrm{~m}$, mainly concentrated in the range of 2000 to $4000 \mathrm{~m}$. There are inversion layers in the cloud, and often more than one layer, which is mainly the frontal inversion (Zhao, 1992). Generally, before the rainstorm occurs, the air is controlled for $700 \mathrm{hpa}$, and the temperature is generally $0^{\circ} \mathrm{C}$ to $4^{\circ} \mathrm{C}$. After that, there is cold air in the lower layer and the rainy weather occurs when the temperature drops below $0^{\circ} \mathrm{C}$. The characteristics of the situation are: there are two fronts in the north and south. One from Baikal, Mongolia to the Yellow Sea in China, known as the North Zhifeng District; the other from the Bay of Bengal to the Yangtze River Basin, known as the South Zhifeng District. There are two troughs of the east trough and the south trough. The east trough moves eastward along the north branch front area and guides the cold air south to form a low-altitude cold layer; the south trough provides the middle layer of warm and humid air. In addition, the cold and high-pressure long axis of the ground is north-south, or north-south-west, and cold air can penetrate the south.

The haze is generated in foggy weather with temperatures below $0^{\circ} \mathrm{C}$. According to the morphological characteristics and formation reasons of smog, it can be divided into two types: granular smog and crystalline smog. In windy weather, when the temperature is between $-2^{\circ} \mathrm{C}$ and $-7^{\circ} \mathrm{C}$ (slightly cold), the cold mist droplets maintain the shape of the droplets and freeze on the ground objects to form a granular icy ice-cream layer with surface undulations. Its structure is relatively crisp and easy to fall after the earthquake. Granular haze not only forms fast, but can grow to a large extent $(\mathrm{Si}, 2002)$. In the breeze or windless weather, when the temperature is between $-10^{\circ} \mathrm{C}$ and $-20^{\circ} \mathrm{C}$ (cold cold), when the humidity exceeds the saturation of the ice surface, the supercooled water droplets or the water vapor in the air directly condense on the ground object, forming Crystal smog, the shape is white furry needle-like crystal, 
with ice crystal flash, the thickness is generally small. When there is no wind, it accumulates on the surface of the whole object, and when it is windy, it is on the windward side. The crystalline haze grows from one side of the object and does not grow at a high rate, so its harmfulness is not large (Si, 2002). Granular haze is more harmful to the icing of wires.

\subsection{Weather Conditions for Ice Formation on Power Lines}

Icing of wires is produced under certain meteorological conditions. According to the weather station observation, the icing of wires often appear under wind speed of $5 \mathrm{~m} / \mathrm{s}$, air temperature between $-10^{\circ} \mathrm{C}-0^{\circ} \mathrm{C}$, relative humidity in the air is above $95 \%$, and the real formation cause disaster weather to wires must meet the following three conditions (Wang et al., 1997):

1) there are supercooled fog droplets or supercooled cloud droplets, which are constantly supplemented by water vapor;

2 ) it is windy but not very windy. It is most easily generated at $3-5 \mathrm{~m} / \mathrm{s}$, and the southeast wind is conducive to the growth of icing of wires;

3) the temperature in $3^{\circ} \mathrm{C}-6^{\circ} \mathrm{C}$ is most serious.

When the wind speed exceeds $5 \mathrm{~m} / \mathrm{s}$, due to the wind power effect, coupled with wire swing, easy to cause the phenomenon of ice outer layer falling off. Smaller southeasterly winds blow moisture onto power lines, causing ice to build up rapidly on the windward side. Temperature plays a very important role in the process of icing of wires.

Severe icing of wires disaster are mostly through many of the icing of wires, so an important meteorological conditions causing severe icing is too cold rain precipitation cloud and the ground below $0^{\circ} \mathrm{C}$ low temperature to maintain a long time. The weather pattern of icing of wires in Guizhou is generally the same as the temperature field and wind field configuration of the high and low layers of the rime, that is, the continuous strong cold air in the north is prevailing from the low layer and the warm and wet air flow in the west of the high layer. Strong cold air coming down the easterly path is essential to keep the ground cold and the deep undercooled layer below the clouds. Many research results indicate that under the stable maintenance of the Ural blocking high pressure and the cutoff low pressure of the Okhotsk sea, it is most beneficial for the strong polar cold air to move southward and enter Guizhou along the easterly path (via Hunan and Hubei) (Zhao, 1992). In January and February 1984, the severe rime ice weather in Guizhou was related to it.

\section{Analysis of Meteorological Characteristics during Icing of Wires}

The meteorological characteristics, such as temperature, wind direction and wind speed, are important reference factors to predict the icing of wires occurrence. Although the icing of wires in the process of Yuriong fog rime weather, but when the rain rime fog weather, icing of wires is not necessarily appear, then the temperature, humidity in a certain range, the size of the wind speed is suitable 
for the wind is conducive to the formation of ice.

\subsection{The Effect of Temperature on the Icing of Wires}

When cloud temperature below zero ice crystals can be formed, when the ice crystals coexist supercooled water droplets in the clouds, because the ice water saturated air pressure is lower than the temperature of the water saturated with water and ice crystals will advantage growth through the water vapor diffusion and this process is carried out on the ice deposits, grew up by the mechanism of ice particles called snow crystals usually used often in a linear scale on 300 as the boundary between the ice and snow crystals (Sheng et al., 2003) moisture diffusion mechanism under the growth of ice crystals shape is controlled by the environmental temperature of wet conditions glaze rime form icing micro physical process, the formation of ice crystals and the cloud is similar.

Temperature range is closely related to the type of icing it by influencing the icing type, thus in the process of icing of wires plays a very important role when by above freezing temperatures fall to minus, can make the supercooled water droplets in the air to freeze on the wire directly, form the glaze, the icing density, strong robustness, ice weight will increase rapidly, the harmfulness of big when the temperature in $3-6$, in addition to the glaze can be generated, is also a lot of advantageous conditions of generation and growth of rime, and wire the heaviest icing hazard when air temperature is below -10 . The formation of mainly crystalline rime results in relatively light ice damage (Zhao, 1992).

Fog persisted throughout the ice observation in 1990. As can be seen from Figure 2(a), (the number of samples of the two observation points are 39.40 and 79 in total), it is found that the temperature change trend of the two observation points is almost the same, and the temperature increases as a whole with the increase of time, accompanied by small fluctuations in the middle. When the temperature curve shows a sharp drop, the fog gradually dissipates.

In addition, in 19901 \# observation point observation process, there was precipitation and rime fog rime weather, then, in 25 hours to 32 hours, 101 hours to 104 hours during the icing of wires, accompanied by rime weather. As can be seen from the temperature change curve in Figure 2(a), icing of wires occurs when the temperature drops, and it is the minimum value of the observation record. Figure 2(b) (initial hanging temperature $-1^{\circ} \mathrm{C}$, initial wind speed $4 \mathrm{~m} / \mathrm{s}$, formal observation started 3 hours later. Sample of 28 and Table 1 showed that the temperature of the icing of wires to keep the phase at $6.0^{\circ} \mathrm{C}-1.8^{\circ} \mathrm{C}$, than fog, glaze rime is low. Generally speaking, the glaze keeps the temperature of phase in $4.5^{\circ} \mathrm{C}-0.8^{\circ} \mathrm{C}$ (Jayaratne, 1991). The rime temperature range and the average temperature of the rime are in this range, but on the high side. The reason lies in the existence of warm fog in both the front and back parts of the observation. Generally, inversion layer exists in the fog to keep the temperature at a high level. In addition, the frequency of rime is small, which makes its statistical significance less. 


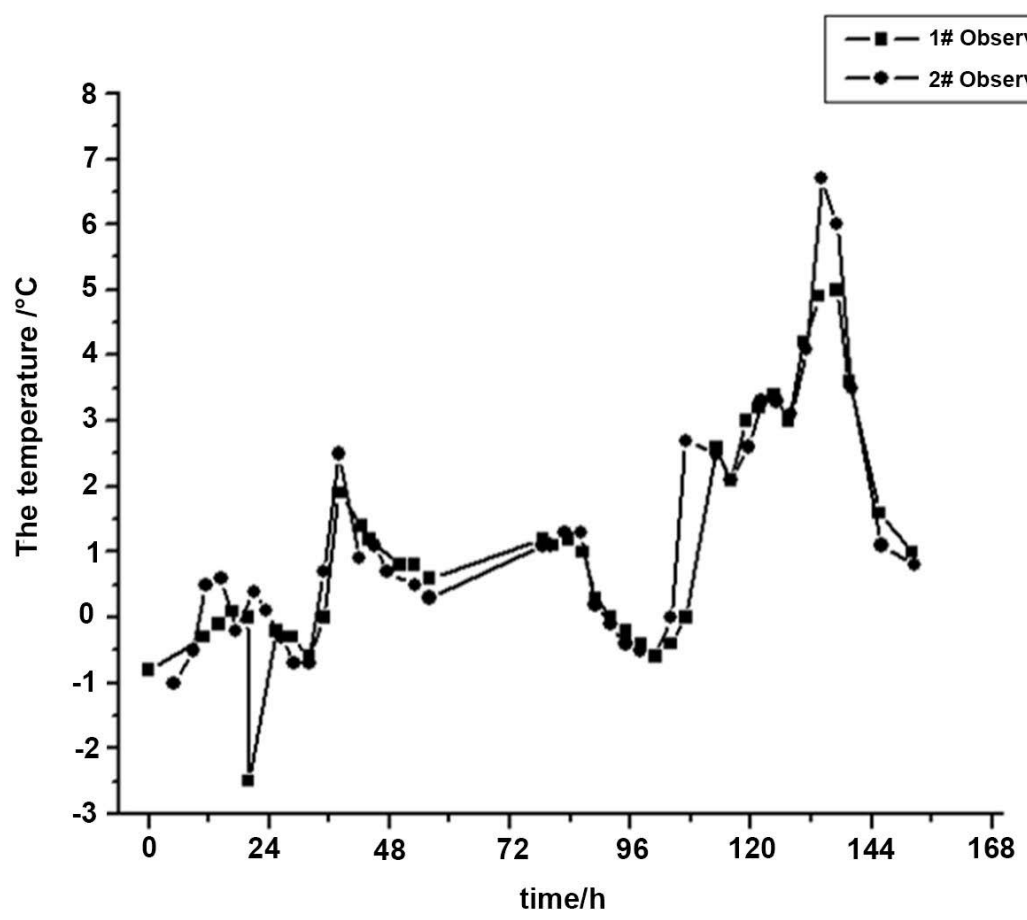

(a)

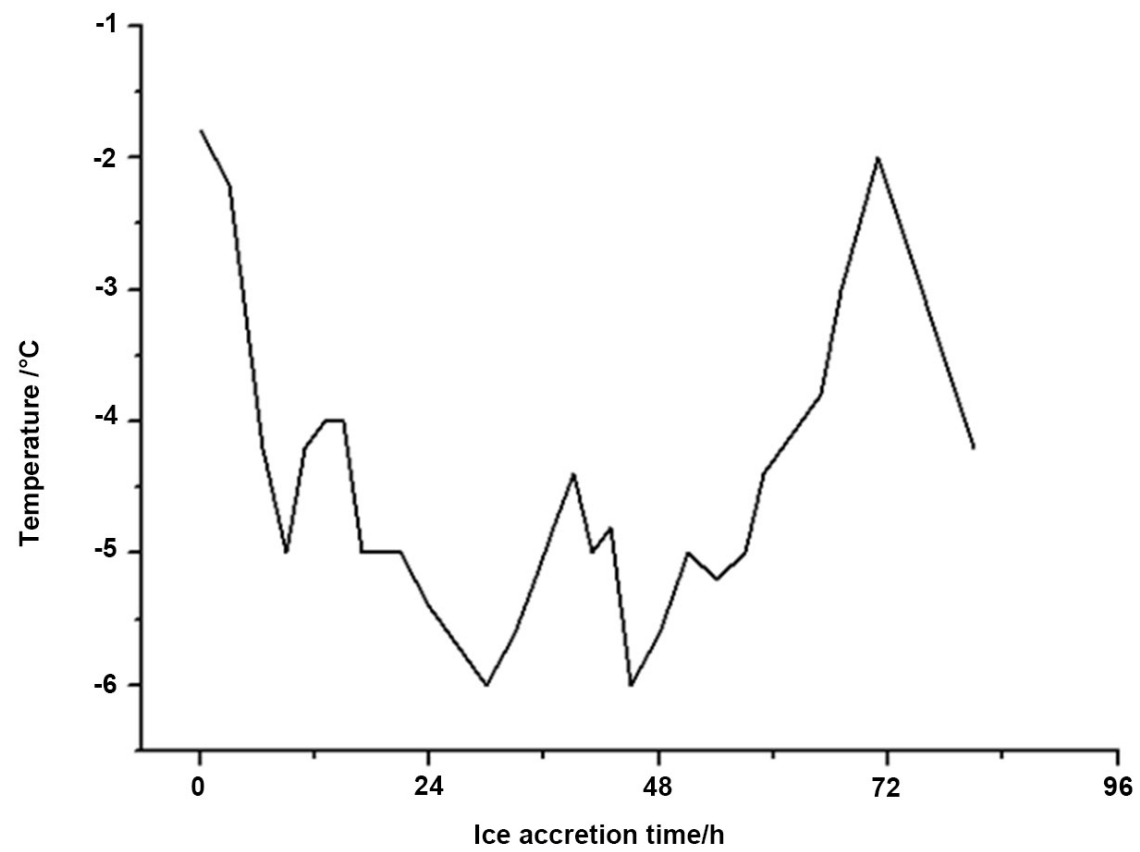

(b)

Figure 2. The temperature change with time during the icing of wires (a) in 1990 at Zunyi Loushan; (b) in 1994 at Guiyang Yunwushan.

\subsection{Influence of Wind Direction and Wind Speed on Icing of Wires}

In the formation of rain and smog, there is a growth process in which cold water droplets and ice crystals collide and freeze, that is, growth. In general, ideally, assuming that all of the supercooled water droplets freeze on the surface after 
Table 1. The temperature during the icing of wires in 1990 and 1994.

\begin{tabular}{|c|c|c|c|c|c|}
\hline \multirow[b]{2}{*}{ Time } & & \multicolumn{4}{|c|}{ fog } \\
\hline & & $\begin{array}{l}\text { Frequency of } \\
\text { occurrence }\end{array}$ & Temperature range $\left({ }^{\circ} \mathrm{C}\right)$ & \multicolumn{2}{|c|}{ Average temperature $\left({ }^{\circ} \mathrm{C}\right)$} \\
\hline \multicolumn{2}{|c|}{1990 year Lushan 1\# } & 32 & $-2.5-5.0$ & \multicolumn{2}{|r|}{1.40} \\
\hline \multicolumn{2}{|c|}{1990 year Lushan 2\# } & 35 & $-1.0-6.7$ & \multicolumn{2}{|r|}{1.46} \\
\hline \multicolumn{2}{|c|}{$\begin{array}{c}1994 \text { year Yunwu } \\
\text { Mountain }\end{array}$} & \multicolumn{4}{|c|}{ None } \\
\hline \multicolumn{3}{|c|}{ Rain and haze } & \multicolumn{3}{|c|}{ Icing of wires } \\
\hline $\begin{array}{l}\text { Frequency of } \\
\text { occurrence }\end{array}$ & $\begin{array}{c}\text { Temperature } \\
\text { range } /{ }^{\circ} \mathrm{C}\end{array}$ & $\begin{array}{c}\text { Average } \\
\text { temperature } /{ }^{\circ} \mathrm{C}\end{array}$ & $\begin{array}{l}\text { Frequency of } \\
\text { occurrence }\end{array}$ & $\begin{array}{l}\text { Temperature } \\
\text { range }\left({ }^{\circ} \mathrm{C}\right)\end{array}$ & $\begin{array}{c}\text { Average } \\
\text { temperature }\left({ }^{\circ} \mathrm{C}\right)\end{array}$ \\
\hline 7 & $-0.8--0.2$ & -0.47 & 5 & $\begin{array}{l}-0.6--0.2 \\
\text { (Rain type) }\end{array}$ & -0.42 \\
\hline \multirow[t]{2}{*}{5} & $-0.6-0.5$ & -0.22 & & None & \\
\hline & Not counting & & 28 & $\begin{array}{l}-6.0--1.8 \\
(\text { Smog type })\end{array}$ & -4.49 \\
\hline
\end{tabular}

they collide with the ice crystals (so-called dry ice growth), the growth of the ice particles can be determined by the continuous collision equation (Alfonso \& Raga, 2017):

$$
\frac{\mathrm{d} m}{\mathrm{~d} t}=E A_{s} q_{w}\left|v_{s}-v_{w}\right|
$$

where $E$ is the collision coefficient between supercooled water droplets and ice crystals, $A_{s}$ is the cross section of ice crystals, $q_{w}$ is the content of cloud water, $v_{s}$ and $v_{w}$ are the falling speed of ice crystals and water droplets respectively. For the actual situation, when the wire is iced, the icing of wires can be regarded as ice crystal, and the thickness of the icing of wires can be regarded as the ice crystal cross section. Thus, the increase in icing of wires is related to the collision coefficient, the cloud water content, and the falling speed of the water droplets. This paper mainly considers the influence of the falling speed of water droplets on the growth of ice accretion. For non-stationary air, the falling speed of water droplets is affected by wind direction and wind speed (Table 2).

Observations in 1990 showed that the winds in the foggy days were mostly southerly and southerly. However, due to the high wind speed of the southeast wind, it was not conducive to the formation of rain, haze and smog, which was not conducive to the formation of icing of wires, resulting in icing of wires during the observation period. The process is short. Moreover, in the icing of wires during the observation point in 1990, the north and northerly winds of 1.5 to 4.8 $\mathrm{m} / \mathrm{s}$ were affected by the direction of the airflow, and the diameter of the ice in the north-south direction was 4 to $8 \mathrm{~mm}$ larger than the east-west direction. When the icing of wires in Lushan occurred in 1994, the wind direction was mostly in the east wind, and the southeast wind also accounted for a considerable proportion.

The smog and rain in Huangshan appeared most near the NW wind direction (Wu et al., 1998) Different from the conclusions of this observation, Zunyi is 
Table 2. Frequency of wind direction during the icing of wires in Zunyi in 1990 and 1994.

\begin{tabular}{|c|c|c|c|c|c|c|c|c|c|c|c|c|c|c|c|c|c|c|}
\hline & Wind direction & $\mathrm{N}$ & NNE & $\mathrm{NE}$ & ENE & E & ESE & SE & SSE & S & SSW & SW & WSW & $\mathrm{W}$ & WNW & NW & NNW & $\mathrm{C}$ \\
\hline 1990 year & Frequency & 6 & 1 & 9 & 0 & 4 & 0 & 15 & 1 & 18 & 1 & 4 & 0 & 4 & 0 & 7 & 1 & 7 \\
\hline 1994 year & Frequency & 0 & 2 & 5 & 0 & 9 & 1 & 8 & 0 & 1 & 0 & 0 & 0 & 0 & 0 & 0 & 0 & 0 \\
\hline Comprehensive & Frequency & 6 & 3 & 14 & 0 & 13 & 1 & 23 & 1 & 19 & 1 & 4 & 0 & 4 & 0 & 7 & 1 & 7 \\
\hline
\end{tabular}

a. There were 78 samples in 1990; there were 26 samples in 1994 (78 simples in 1990; 26 simples in 1994).

located in the northern part of Guizhou Province. The terrain is high in the west and low in the east, with an average elevation of over $1000 \mathrm{~m}$. In the west of Zunyi, there is Dagu Mountain, a mountain range that runs from northeast to southwest. The terrain is surrounded by mountains on the west, north and south. Affected by the topography, the cold air takes the east road from the lower level into Zunyi, forming a cold air cushion. The warm air moved from the west, making the rain easy to happen.

In the physical model of icing of wires (Zhang et al., 2006),

$$
W_{m}=\beta A B \tau V \sin \theta
$$

where $W_{m}$ is the weight of accumulated ice, $\beta$ is the freezing coefficient, $A$ is the cross-sectional area of airflow before undisturbed, $B$ is the liquid water content per unit volume, $\tau$ is the period of accumulated ice, $V$ is the horizontal wind speed, and $\theta$ is the Angle between airflow and wires. It can be known that the weight of ice $W_{m}$ is proportional to the component of wind speed $V \sin \theta$. The statistical analysis of the relationship between the average wind speed component and the weight of icing of wires shows that the weight of both types of ice accretion increases with the increase of wind speed. The magnitude of the increase is larger than that of the hail, and the wind speed is larger. The faster the wet snow type grows, it means that the wind speed has a greater impact on the growth of wet snow type ice. However, Figure 3 shows that the wind speed at the occurrence of icing of wires is mostly 1.0 to $4.5 \mathrm{~m} / \mathrm{s}$. The reason is that when the wind speed is small, it is not suitable for the supercooled water droplets to land on the electric wires; if the wind speed is too large, the degree of oscillation of the electric wires will increase, the hydrodynamic structure around the electric wires is changed, and the adhesion of the ice accretion is reduced, thereby causing deicing.

\section{Icing of Wires Characteristics Analysis}

Some characteristics of the icing of wires itself, such as the macroscopic icing of wires duration, the critical icing of wires date of ice accidents and the number of ice damages, and various ice accretion parameters, are important reference factors for ice accidents, and also the power sector. The parameters should be considered when designing overhead lines.

\subsection{Macroscopic Features of Icing of Wires}

From the theoretical formula of icing of wires: the amount of icing of wires (Tan, 1982), 


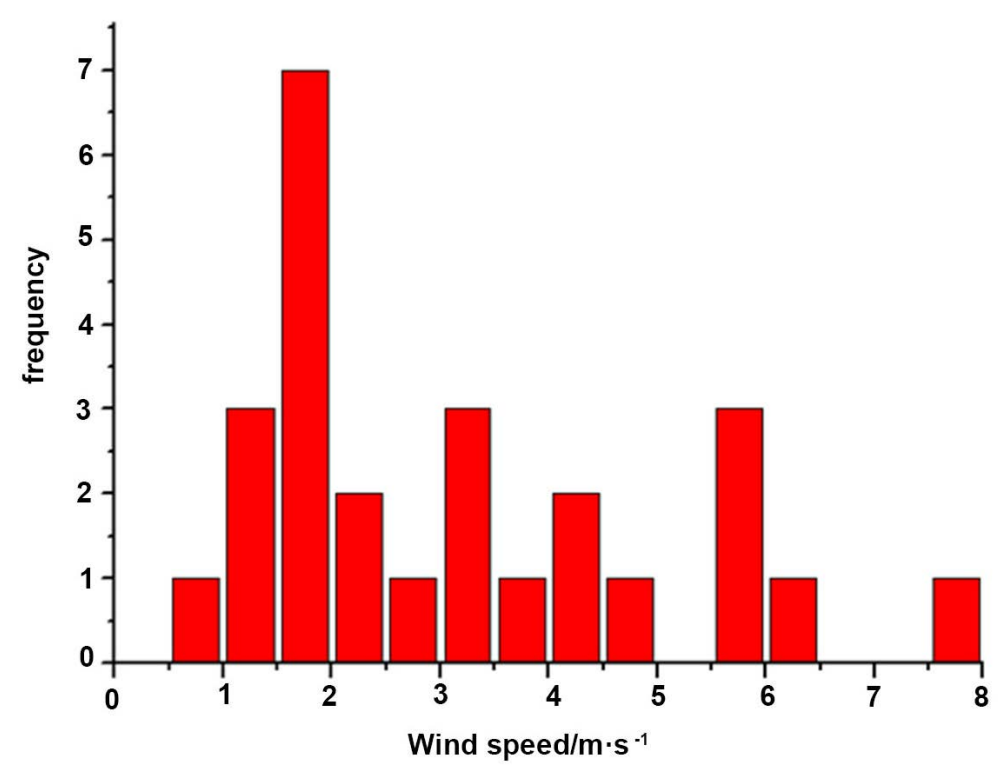

Figure 3. The frequency of the wind during the icing of wires in 1990 (at Zunyi, 26 simples).

$$
M=E \cdot N \cdot D \cdot W \cdot \tau \cdot V \cdot \sin \theta,
$$

the amount of icing of wires is proportional to the water content of the cloud droplet and the icing of wires time. Due to the lack of information on the liquid water content, the length of the ice accretion is used to measure the strength of the ice. When the water content of the cloud is too strong or too weak, only the icing of wires time is used to measure the strength of the ice, which is poorly representative. In fact, the number of ice accretion days in the mountains may be slightly longer than that in the nearby weather stations, but the local areas are similar and in the same atmospheric circulation background, the two are very close.

Figure 4 shows that the maximum number of icing of wires days in Shuicheng and Kaiyang occurred in 1984 during an ice accretion. According to the analysis of the ice accidents recorded by the electric power department, this year is the heaviest ice injury year in Guizhou history. It has caused the collapse of Guizhou Power Grid into four blocks, namely Guiyang, Dukai, Liupanshui and Zunyi. In the province, $37 \%$ of the lines were tripped, a total of 131 times, with an average of 4 trips per day (Luo, 1994).

It can be seen from Figure 5 that the first time the ice accident occurred in Shuicheng and Kaiyang was mainly on the 4th to 9th of the ice accretion process, and the most frequent occurrence of ice damage occurred on the 7 th day of the ice accretion process. The earliest occurrence of ice accidents in the two places was on the 4th day of ice accretion. After that, the frequency of ice accidents showed an upward trend, reaching the maximum on the 7 th day and then falling rapidly. It is concluded that the critical icing of wires days in Shuicheng and Kaiyang are the fourth day of the rainy days and the number of haze days, and the probability of occurrence of ice accidents is on the rise. 


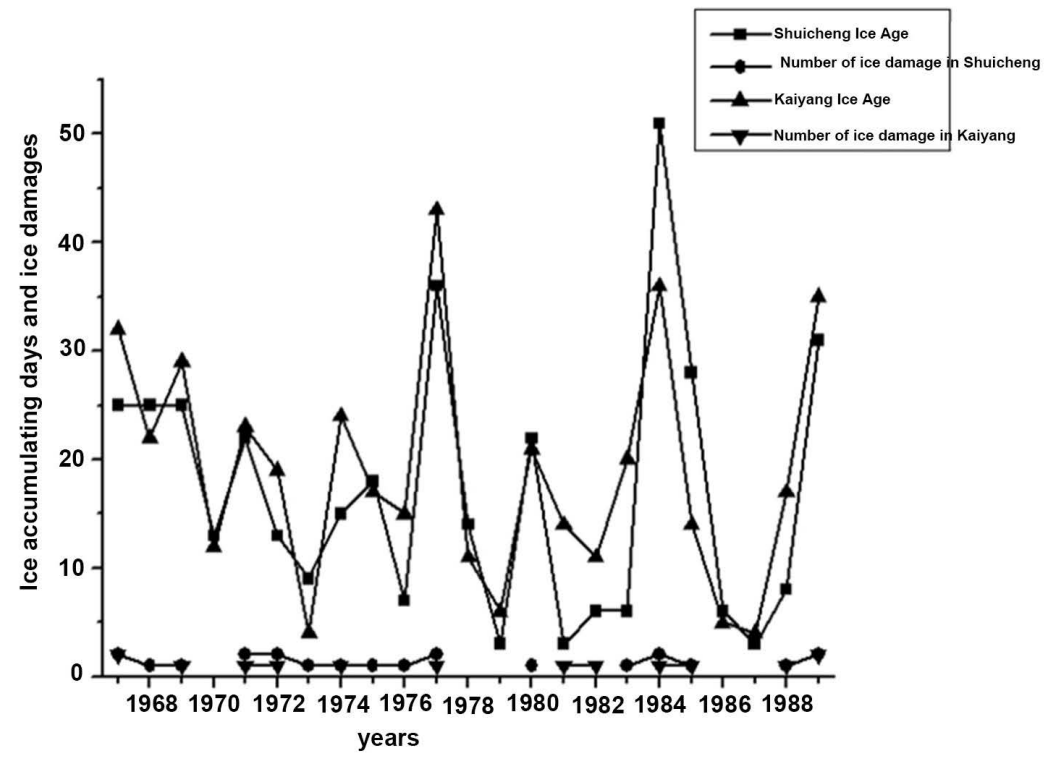

Figure 4. The icing continued days and the icing disaster times at Shuicheng and Kaiyang.

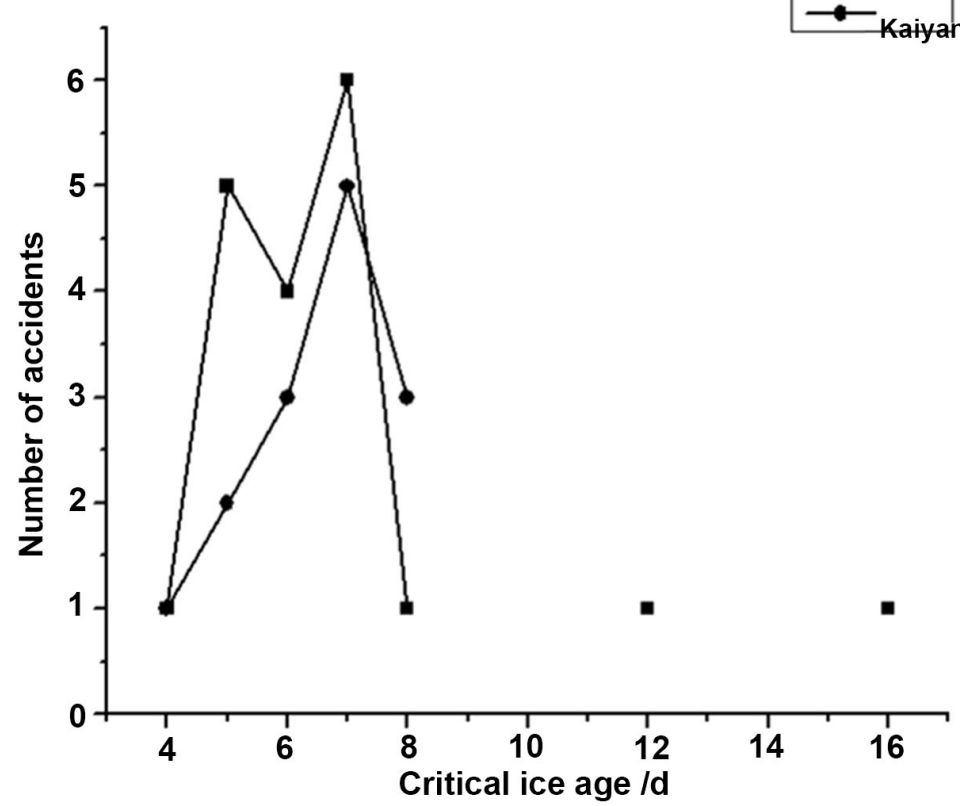

Figure 5. The icing continued days and the icing disaster times at Shuicheng and Kaiyang (at Shuicheng, 19 simples and; at Kaiyang 11 simples).

Table 3 shows that in different durations of ice accretion, the ice disaster rate of Shuicheng is higher than that of Kaiyang. During the icing process lasting 3 to 10 days, the comprehensive ice disaster rate in the two places was $31 \%$; in the icing of wires process lasting 11 to 20 days, $53 \%$ of the ice accidents occurred; the icing of wires lasted for 21 to 30 days. In the process, all ice accidents occurred. It indicates that the longer the icing of wires lasts, the higher the ice disaster rate. 
Table 3. The disaster rate of the icing disaster during 1967-1989 at Shuicheng and Kaiyang.

\begin{tabular}{cccccccccc}
\hline & \multicolumn{3}{c}{ Shuicheng } & \multicolumn{3}{c}{ Kaiyang } & \multicolumn{3}{c}{ comprehensive } \\
\cline { 2 - 10 } Icing of wires days & Ice accretion & $\begin{array}{c}\text { Ice damage } \\
\text { number }\end{array}$ & $\begin{array}{c}\text { Disaster } \\
\text { rate }\end{array}$ & Ice accretion & $\begin{array}{c}\text { Ice damage } \\
\text { number }\end{array}$ & $\begin{array}{c}\text { Disaster } \\
\text { rate }\end{array}$ & $\begin{array}{c}\text { Ice accretion } \\
\text { Ice damage } \\
\text { number }\end{array}$ & $\begin{array}{c}\text { Disaster } \\
\text { rate }\end{array}$ \\
\hline $1-10$ & 23 & 9 & $39 \%$ & 25 & 6 & $24 \%$ & 48 & 15 & $31 \%$ \\
$11-20$ & 13 & 11 & $85 \%$ & 19 & 6 & $32 \%$ & 32 & 17 & $53 \%$ \\
$21-30$ & 2 & 2 & $100 \%$ & 1 & 1 & $100 \%$ & 3 & 3 & $100 \%$ \\
\hline
\end{tabular}

\subsection{Changes in Ice Accretion Parameters}

The ice accretion parameter is an important parameter for whether the icing of wires can cause an ice accident, mainly due to ice accretion diameter, ice accretion thickness, ice accretion weight and ice accretion density.

\subsubsection{Changes in Ice Diameter and Thickness during Icing of Wires}

An ice accretion process can generally involve several stages of development, maintenance, collapse, or ablation of ice accretion. These stages may occur in sequence, or may be repeated and repeated, and the length of time varies. Often during the total growth of icing of wires, there will be some small collapses.

Wind, temperature, precipitation (humidity), and sunshine have a greater impact on the icing of wires. When the temperature rises or the precipitation is too small, the icing of wires grows. When the sun shines, the metal wire will warm up faster. When the temperature is higher than the air temperature, the ice on the wire will collapse easily. Ice accretion is formed and developed under severe weather conditions such as low temperature, high humidity, low wind, fog or precipitation; when the clouds rise, the precipitation stops, and the weather begins to turn well; when the temperature rises, the sunshine appears. When the wind increases, it is easy to collapse and melt (China Meteorological Administration, 2003). Therefore, the development of ice accretion can be judged according to the evolution trend of meteorological elements.

Figure 6 and Figure 7 show that as the ice accretion time is extended, the long ice thickness of various types of electric wires tends to increase as a whole, and there is a different degree of reduction between them, that is, a small collapse phenomenon occurs, and then the product is accumulated. Ice has started a new growth. The maximum value of an ice accretion process occurs before collapse or ablation. Combined with the temperature data, the temperature slowly decreases in the early stage of observation. At this time, the ice diameter and thickness increase continuously, and the ice accretion process is in the palm stage. When the temperature rises, the ice diameter and thickness no longer increase, and it is in the maintenance stage. The ice process is in the holding phase; when the temperature peaks, the ice diameter and thickness decrease, and the ice accretion process collapses; when the temperature continues to rise, the ice diameter and thickness decrease continuously, and the ice accretion process is in the dissipating stage. 


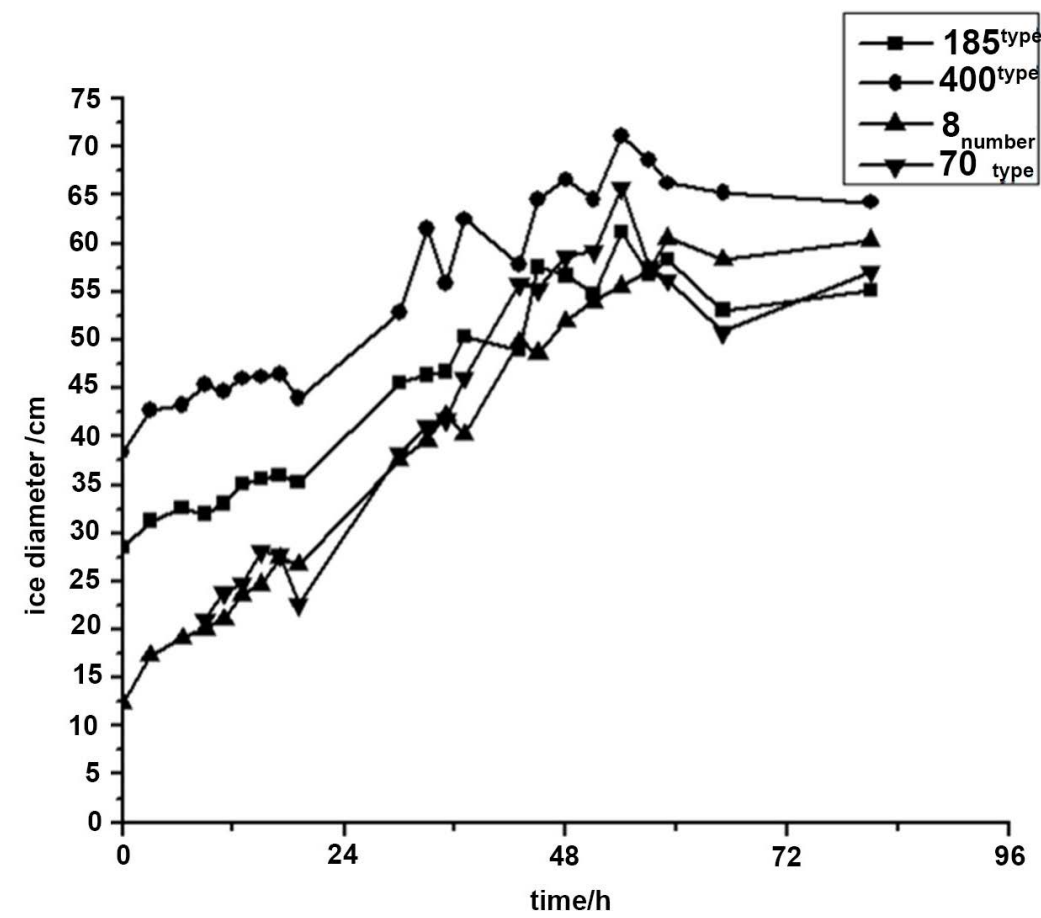

Figure 6. The icing diameter change with time during the icing of wires in 1994 (93 samples).

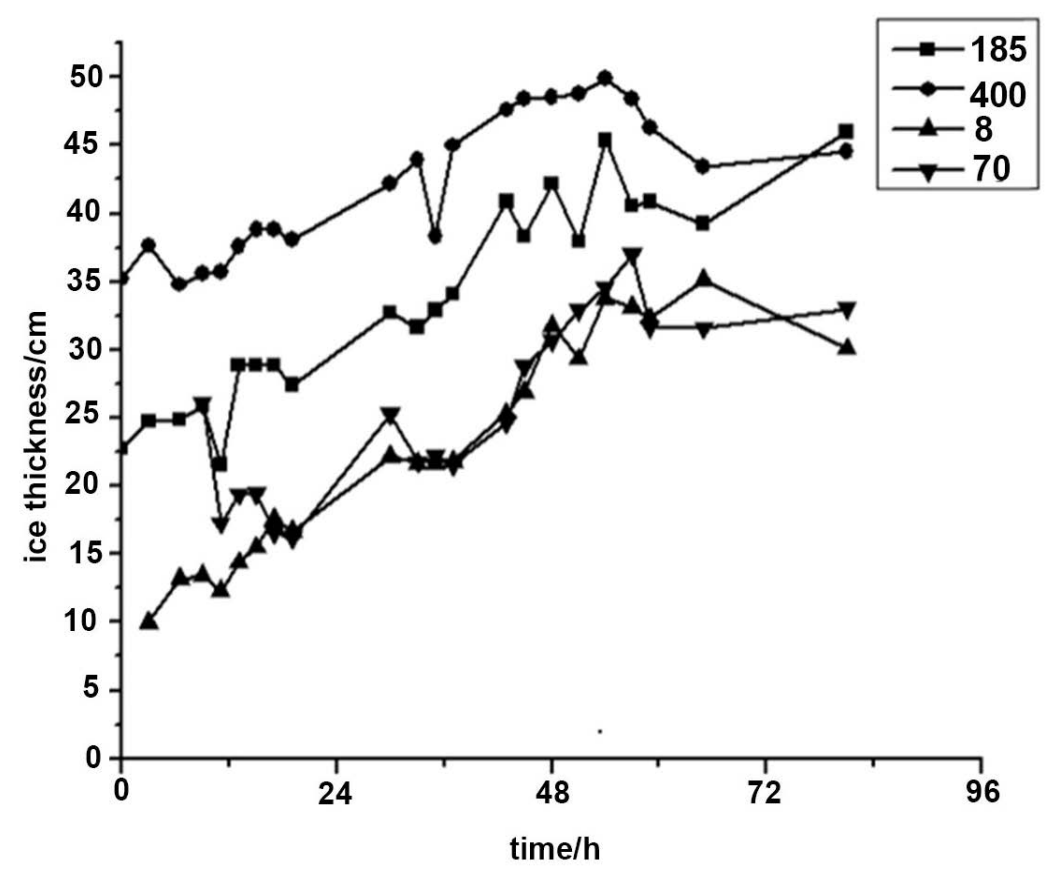

Figure 7. The icing thickness change with time during the icing of wires in 1994 (92 samples).

\subsubsection{Ice Density and Ice Weight}

When the power sector designs the thickness of icing of wires, the uniform density of ice is $0.9 \mathrm{~g} / \mathrm{cm}^{3}$ (Luo, 1994). In the observation of actual icing of wires, it was found that different types of ice accretion have different ice densities. The 
data show that the weight of the rain-type ice is between 24 and $152 \mathrm{~g}$, the density is between 0.1034 and $0.8488 \mathrm{~g} / \mathrm{cm}^{3}$; the weight of the smog-type ice is between 40 and $76 \mathrm{~g}$, and the density is between 0.1157 and $0.5016 \mathrm{~g} / \mathrm{cm}^{3}$ (Gates, 1986). It can be seen from the density that the raindrop type changes a lot, while the haze type changes a little.

The ice density and ice diameter on the wires are not exactly the same every time the ice accretion process. For icing of wires, the third parameter can be calculated by knowing any two of the ice density, the ice diameter, and the ice load (i.e., the weight of the ice). Ice damage prevention work can be carried out in conjunction with this result and the design criteria of the wire. Table 4 shows the measured data of LGJ185 wire, which shows that the ice diameter is positively correlated with the ice load at a certain ice density. According to Table 4 and Table 5, it can be judged that the ice diameter of the ice faults on these two lines is $100-400 \mathrm{~mm}$, and the maximum ice weight is $15 \mathrm{~kg}$. Therefore, the average ice density of these two places can be calculated to be $0.2-0.5 \mathrm{~g} / \mathrm{cm}^{3}$.

\section{Conclusion}

When the ice crystals coexist with the supercooled water droplets, the ice crystals gain an advantageous growth because the saturated water pressure on the ice surface is lower than the saturated water pressure on the water surface at the same temperature. During the icing of wires, this process is carried out by diffusion of the subcooled water droplets and deposition on the wires. The temperature affects the type of icing of wires on the wire by the freezing process that affects the cooling of the water droplets. Thus, the temperature range of the smog-type icing of wires in Zunyi is $-6.0^{\circ} \mathrm{C}$ to $-1.8^{\circ} \mathrm{C}$.

The growth of icing of wires is related to the collision coefficient, the cloud water content and the falling speed of water droplets. This paper analyzes the wind direction and wind speed to influence the growth of icing of wires by changing the falling speed of water droplets. In Zunyi, east wind and southeast wind are conducive to the icing of wires formation.

The meteorological records of Shuicheng and Kaiyang indicate that the longer the icing of wires, the higher the incidence of ice damage. The number of critical

Table 4. The icing of wires diameter at different ice density at LGJ185 wire.

\begin{tabular}{ccccc}
\hline Ice load kg/m & Ice density 0.9 & Ice density 0.5 & Ice density 0.3 & Ice density 0.2 \\
\hline 2.26 & 60 & 78 & 98 & 122 \\
4.23 & 80 & 106 & 134 & 166 \\
6.782 & 100 & 131 & 170 & 208 \\
9.891 & 120 & 160 & 204 & 252 \\
13.564 & 140 & 183 & 240 & 294 \\
17.704 & 160 & 212 & 274 & 336 \\
\hline
\end{tabular}

a. (The icing of wires diameter $20 \mathrm{~mm}$, density $\mathrm{g} / \mathrm{cm}^{3}$, icing diameter $\mathrm{mm}$ ). 
Table 5. The icing parameter when icing of wires disaster on Shuipan and Jiuzun lines.

\begin{tabular}{|c|c|c|c|c|c|}
\hline \multirow[b]{2}{*}{ Ice age } & \multicolumn{3}{|c|}{ Shuipan Line } & \multicolumn{2}{|c|}{ Jiuzun Line } \\
\hline & Ice diameter $(\mathrm{mm})$ & $\begin{array}{c}\text { Density }\left(\mathrm{g} / \mathrm{cm}^{3}\right) \\
\text { (Observation) }\end{array}$ & $\begin{array}{l}\text { Ice accretion } \\
\text { type }\end{array}$ & Ice diameter $(\mathrm{mm})$ & $\begin{array}{c}\text { Ice accretion } \\
\text { type }\end{array}$ \\
\hline 1967 & 300 & & Smog type & 200 & Smog type \\
\hline 1968 & 300 & & Smog type & & \\
\hline 1969 & & & & 280 & Smog type \\
\hline 1970 & 380 & 0.34 & Smog type & & \\
\hline 1971 & 380 & & Smog type & & \\
\hline 1974 & 240 & 0.5 & Smog type & 100 & Rain type \\
\hline 1975 & 200 & & Smog type & & \\
\hline 1977 & 130 & & Smog type & & \\
\hline 1980 & 230 & & Smog type & & \\
\hline 1981 & & & Smog type & 180 & Smog type \\
\hline 1984 & 400 & & Smog type & 210 & Smog type \\
\hline 1989 & 260 & & & & \\
\hline
\end{tabular}

ice accretion days in these two places is the fourth day of the number of days of rain and haze, and the probability of occurrence of ice accidents is on the rise.

The variation of ice diameter and thickness during ice accretion reflects the different stages of an ice accretion process. According to the fluctuation of ice diameter and thickness, the development of ice accretion process can be obtained. When the ice diameter and thickness continue to increase, the ice accretion process is in the palm stage; when the ice diameter and thickness no longer grow, in the maintenance phase, the ice accretion process is in the holding phase; when the ice accretion diameter and thickness decrease, the ice accretion process collapses; as the ice diameter and thickness continue to decrease, the ice accretion process is in the dissipating phase.

For icing of wires, the third parameter can be calculated by knowing any two parameters of ice density, ice diameter and ice load (i.e. ice weight). Ice damage prevention work can be carried out in conjunction with this result and the design criteria of the wire.

\section{Conflicts of Interest}

The authors declare no conflicts of interest regarding the publication of this paper.

\section{References}

Alfonso, L., \& Raga, G. B. (2017). The Impact of Fluctuations and Correlations in Droplet Growth by Collision-Coalescence Revisited Part 1: Numerical Calculation of Post-Gel Droplet Size Distribution. Atmospheric Chemistry \& Physics, 17, 6895-6905.

https://doi.org/10.5194/acp-17-6895-2017 
China Meteorological Administration (2003). Specifications for Surface Meteorological Observations (pp. 92-95).

Gates, E. M. (1986). Simulated Atmospheric Rime Icing of Some Wind Speed Sensors. Journal of Atomospheric and Oceanic Technology, 3, 273-282. https://doi.org/10.1175/1520-0426(1986)003<0273:SARIOS>2.0.CO;2

Jayaratne, E. R. (1991). Elctric Charge Separation during the Fragmentation of Rime in an Ariflow. Journal of Amospheric Sciences, 48, 2492-2495. https://doi.org/10.1175/1520-0469(1991)048<2492:ECSDTF>2.0.CO;2

Liu, H. Y., Zhou, D., Fu, J. P. et al. (2001). Study on the Simple Model of Wire Rain and Ice Coating. Chinese Journal of Electrical Engineering, 21, 44-47.

Loxowski, E. P., Stallabrass, J. R., \& Hearty, P. F. A. (1983). The Icing of an Unheated, Nonrotating Cylinder. Part II. Icing Wind Tunnel Experiments. Journal of Applied Meteorology, 22, 2063-2074. https://doi.org/10.1175/1520-0450(1983)022<2063:TIOAUN>2.0.CO;2

Luo, N. (1994). The Relationship between Rain and Fog and Meteorological Accidents in Meteorological Records. Guizhou Meteorology, 18, 10-20.

Makkonen, L. (1981). Estimating Intensity of Atmospheric Ice Accretionon Stationary Structures. Journal of Applied Meteorology, 20, 595-600. https://doi.org/10.1175/1520-0450(1981)020<0595:EIOAIA >2.0.CO;2

Makkonen, L. (1984). Modeling of Ice Accretion on Wires. Journal of Climate and Applied Meteorology, 23, 929-939. https://doi.org/10.1175/1520-0450(1984)023<0929:MOIAOW >2.0.CO;2

Sheng, Y. X., Mao, J. T., \& Li, J. G. (2003). Atmospheric Physics (pp. 304-343). Beijing: Peking University Press.

Si, D. (2002). Frost (pp. 52-64). Beijing: Meteorological Press.

Tan, G. R. (1982). Discussion on Some Microclimate Characteristics of Wire Ice Accumulation. Acta Meteorologica Sinica, 40, 13-23.

Wang, R. R., Xie, Z. Z., \& Zhang, S. L. (1997). Analysis of Observation Data and Construction of High Voltage Transmission Lines in Nanling Ice-Covered Meteorological Station. Shanxi Meteorology, 4, 16-18.

Wu, Y. X., Wang, J. B., Wang, K. Q. et al. (1998). Climatic Characteristics of Snow, Rain and Haze in Huangshan Mountain. Meteorology, 25, 48-52.

Zhang, G. Q., Zhang, J. K., Pei, D. L. et al. (2006). Preliminary Observation and Analysis of Wire Ice Accumulation in Eastern Qinghai. Journal of Applied Meteorology, 17, 508-510.

Zhang, H. N. (1999). Experience in the Observation of Wire Ice Accumulation. Gansu Meteorology, 17, 35-36.

Zhao, C. (1992). Cloud Characteristics and Circulation Background of the Accumulation Process of Rain in Guizhou Province. Meteorology, 21, 48-50.

Zhu, G. G., Lin, J. R., Shou, S. W. et al. (2000). Principles and Methods of Meteorology (pp. 313-318). Beijing: Meteorological Press. 